Article

\title{
The Social Support Scale (MOS-SSS): Standardizing with Item References
}

\author{
Daniela Sacramento Zanini ${ }^{1, *}$ \\ Orcid.org/0000-0003-2515-2820 \\ Evandro Morais Peixoto ${ }^{2}$ \\ Orcid.org/0000-0003-1007-3433 \\ Tatiana de Cássia Nakano ${ }^{3}$ \\ Orcid.org/0000-0002-5720-8940 \\ 'Pontifícia Universidade Católica de Goiás, Goiânia, GO, Brasil \\ ${ }^{2}$ Universidade de Pernambuco, Garanhuns, PE, Brasil \\ ${ }^{3}$ Pontificia Universidade Católica de Campinas, Campinas, SP, Brasil
}

\begin{abstract}
The Social Support Scale (MOS-SSS) aims to assess the extent to which the person has the support of others to face stressful situations. It is a widely used scale, but there is a shortage of studies evaluating its interpretative rules. This study aims to establish standards and cutoffs for MOS-SSS. The study included 998 people of both sexes, aged between 12 and 73 years $(M=27.18, S D=9.90)$, from different sampling strata $(61.7 \%$ college students, $14.7 \%$ of patients in treatment infertility; $10.1 \%$ of patients in treatment for eating disorder and obesity, $8.7 \%$ of patients after bariatric surgery, and $4.8 \%$ of patients treated for burns). The model of partial credits was used to establish standards relating to items by the procedure item-persons map. Rules have been established based on the processing procedure of the total score theta, which will enable the practical application of the results. The data will serve as a reference standard for the scores obtained in different studies for professionals who use this scale.
\end{abstract}

Keywords: Social interaction, health, standards, item response theory, psychological test.

\section{Escala de Apoio Social (MOS-SSS): Proposta de Normatização com Referência nos Itens}

\section{Resumo}

A Escala de Apoio Social (MOS-SSS) visa avaliar em que medida a pessoa conta com o apoio de outras para enfrentar situações estressantes. É uma escala amplamente utilizada, contudo há uma escassez de estudos que avaliem suas normas interpretativas. O presente estudo visa estabelecer normas e pontos de corte para MOS-SSS. Participaram deste estudo 998 pessoas de ambos os sexos, com idades entre $12 \mathrm{e}$ 73 anos $(M=27,18, D P=9,90)$, de diferentes estratos amostrais $(61,7 \%$ estudantes universitários; $14,7 \%$ pacientes em tratamento para infertilidade; $10,1 \%$ pacientes em tratamento para transtorno alimentar e obesidade; $8,7 \%$ submetidos à cirurgia bariátrica; e 4,8\% pacientes em tratamento para queimaduras). O modelo de créditos parciais foi empregado para estabelecimento de normas com referência nos itens,

Endereço para correspondência: Rua 9, n. 769, Apto. 702, Setor Oeste, Goiânia, GO, Brasil 623215-1371. Fone: (62)99841664.E-mail: dazanini@yahoo.com, epeixoto_6@hotmail.com e tatiananakano@hotmail.com 
por meio do procedimento Mapa de item-pessoas. Foram estabelecidas as normas com base no procedimento de transformação da pontuação total em theta, o que possibilitará a aplicação prática dos resultados obtidos. Os dados obtidos servirão como como norma de referência para as pontuações obtidas em diferentes estudos para profissionais que utilizam esta escala.

Palavras-chave: Interação social, saúde, normas, teoria de resposta ao item, teste psicológico.

\section{Escala de Apoyo Social (MOS-SSS): Propuesta de Normalización con Referencia a los Items}

\section{Resumen}

La Escala de Apoyo Social (MOS-SSS) tiene como objetivo evaluar el grado en que la persona tiene el apoyo de los demás para hacer frente a diferentes situaciones estresantes. Es una escala de larga utilización, pero hay una escasez de estudios para evaluar sus normas interpretativas. Este estudio tiene por objeto establecer las normas y los puntos de corte para la MOS-SSS. El estudio incluyó 998 personas de ambos sexos, con edades comprendidas entre 12 y 73 años $(M=27.18, D E=9.90)$, de diferentes estratos de muestreo $(61,7 \%$ estudiantes universitarios, $14,7 \%$ pacientes en tratamiento infertilidad; $10,1 \%$ pacientes en tratamiento por trastornos de la alimentación y obesidad, $8,7 \%$ pacientes pós cirugía bariátrica, y 4,8\% pacientes tratados por quemaduras). Se utilizó el modelo de créditos parciales para establecer normas relativas a los ítems por el procedimiento del mapa ítem-persona. Las normas se han establecido sobre la base del procedimiento de tramitación de la theta total de puntos, lo que permitirá la aplicación práctica de los resultados. Los datos servirán como como patrón de referencia para las puntuaciones obtenidas en diferentes estudios para los profesionales que utilizan esta escala.

Palabras clave: Interación social, normas, teoria de respuesta al ítem, test psicológico.

Ever since the 1970 s, interest in the study of the effect of social relationships on people's health has been the subject of research in many different areas. The study gained momentum through research demonstrating how social relationships, in their different forms, were related to better predictors of health in individuals, better social adaptation, protecting against the negative effects of stress and reducing morbidity and mortality (Cobb, 1976; Dantas, Araújo, Paulino, \& Maia, 2012; Griep, Chor, Faerstein, Werneck, \& Lopes, 2005; Sherbourne \& Stewart, 1991). Among the types of interpersonal relationships that have an impact on health, Sherbourne and Stewart (1991) distinguish the concepts of social network structure and support. A social network is a group of people with which an individual maintains contact or has some form of social connection. The evaluation of this supposedly reveals the individual's level of social integration.

On the other hand, social support may be considered as something which relates to the resources placed at their disposal by other people, in cases of need. The evaluation of this, as well as indicating how socially integrated the individual is, also shows the degree to which interpersonal relations correspond to particular functions and offer support to the individual in times of crisis or readaptation. In other words, a social network may be conceived as a social structure through which support is provided (Griep, 2003), where as social support refers to the functional or qualitative dimension of the social network (Griep et al., 2005).

Gonçalves, Pawlowski, Bandeira and Piccinini (2011) conducted a survey of the Indexpsi, Pepsic, SciELO and Lilacs indexers with the aim of investigating how social support was evaluated in Brazilian studies carried out between 1987 and 2007. The authors found 59 studies which addressed the evaluation of social support in Brazilian samples and noted an increase in recent years in the number of Brazilian studies that include an evaluation of social support. 
These studies use a variety of methods to evaluate social support, though predominantly using interview techniques to investigate, in particular, perceived versus received support. Nevertheless, when they use scales to evaluate social support, the majority chose the Social Support Scale from the Estudo Pró-Saúde (pro-health study) above the others. Lastly, the authors point to the scarcity of information about the reliability and validity of the original tools and adaptations made for Brazil in the research conducted, and stress the need for systematic studies to establish the reliability, validity and standardization of these tools for them to be considered adequate for use in Brazil.

\section{The MOS-SSS Social Support Scale}

Developed for the Medical Outcome Study (Sherbourne \& Stewart, 1991), the MOS-SSS Social Support Scale aims to evaluate the degree to which an individual relies upon the support of others to cope with different life situations. Although developed to be applied to chronic patients, its use has been extended to include different populations due to its ease of application (19 items answered by means of a five-point Likerttype scale) and good psychometric quality demonstrated in different studies using diverse populations and scenarios (Gómez-Campelo et al., 2014; Pais-Ribeiro \& Ponte, 2009). In the study of the search for evidence of validity, the original tool had an internal structure made up of five factors, identified as social support of the following types: emotional and informational support; material support; affective support and support with positive social interaction, and internal consistency indices greater than 0.91 (Sherbourne \& Stewart, 1991).

This scale was subsequently translated and adapted for use in Brazil by Griep et al. (2005). This version was used in a variety of national studies conducted using this set of tools. Zanini, Verolla-Moura and Queiroz (2009) investigated the tool's factorial structure in a sample composed of 129 university students and found four dimensions (emotional/ informational support, social interaction, material support and affective social support), similar to the original model, comprising five factors. The difference lies in the fact that, in the Brazilian analyses, two factors were condensed into one (emotional and informational). Internal consistency disclosed good indices of measurement suitability for the studied population, with alpha indices ranging from 0.76 to 0.95 .

Another study, developed by Griep et al. (2005), with 4,030 technical/ administrative university staff members, indicated the existence of three factors: affective + positive social interaction, emotional + informational, and material. Once again, the presence of similar elements can be seen, but now with the grouping of factors related to the factors positive social interaction and affective support. With regard to the indices of internal consistency, these ranged from 0.83 to 0.92 .

Lastly, Zanini and Peixoto (2016) evaluated the pertinence of the different factorial models proposed for the MOS-SSS in Brazilian studies with different sampling groups. The results exhibited a better quality of fit in the model comprising four factors (emotional/ informational support; social interaction; material support and affective social support), the same ones found in Zanini et al. (2009). Moreover, the total invariance was demonstrated (configural, metric and scalar) of the factorial model when comparing the different sampling strata: university students, patients being treated for infertility, patients receiving treatment for dietary disorders and obesity, patients subjected to bariatric surgery, and patients being treated for burns, as well as when separated according to sex. This indicates the equivalence of the factorial model, factor loads and measurements obtained for the items among the sampled groups (controlling the differences in the latent variables). According to Santos and Primi (2014), locating invariance in the metric and scalar models equates to the nonexistence of differential item functioning (DIF) in parameter (a) discrimination, and difficulty with the Item Response Theory (IRT) in parameter (b).

Lastly, using the Partial Credit Model (PCM), the authors found that the items evaluated the central part of the latent constructs proposed by the factors, with difficulty indices close to the 
mean value (anchored to 0 ) and adequate Infit/ Outfit indices, as well as precision indicators, Cronbach's alpha coefficients, which ranged between 0.83 and 0.92. However, although studies that searched for evidence of validity and other psychometric properties had already been developed with the Brazilian version of the tool, and despite its widespread use, studies providing psychological meaning to the results obtained using the MOS-SSS, are still scarce. In general terms, the analysis of the results is performed using gross scores in correlational studies for intrasample comparative analysis (e.g. Yun, Kang, Lim, Oh, \& Son, 2010) or through an analysis of the levels of scoring by means of the distribution of the study itself (Andrade et al., 2005).

Andrade et al. (2005) classified social support according to the distribution of the sample scores for each factor in the tool, classifying the outcome in tertiles: low, medium and high scores for each factor. This type of analysis, albeit statistically appropriate and serving the objectives of the specific research studies, does not permit comparison between studies. In other words, it allows for an effective intra-study analysis but is not efficient in analyzing this sample's level of social support in comparison with other studies and/or sampling strata. This difficulty would be resolved by conducting studies into the standardization of scales, so that the results that are capable of being interpreted for the pertinent research tool may be known.

With the objective of providing a contribution to fill this gap, this study resorted to using the Item Map procedure based on IRT, which has been indicated as an alternative for the performance of norm-referencing on the items (McClarty, 2013; Primi, Wechsler, Nakano, Oakland, \& Guzzo, 2014; Wyse, 2013). According to Embretson and Reise (2000), one of the advantages of this procedure is the access to the way in which people describe themselves by means of the item content, so as to provide psychological meaning to an individual's results by analyzing the component items of the tool. To this effect, the item parameter (difficulty, identified by the letter $b$ ) and individual parameter (level of latent trait, identified by the Greek letter $\theta$ ) are estimated using IRT. Through the association of these parameters, a procedure known as calibration, the interpretation becomes referenced to the item.

The implementation of the process of normreferencing on the items is based on the following assumptions: (a) understanding of the properties of the tools such as internal structure and the structure of the Likert scale, (b) understanding of the item parameter (indices of difficulty and fit) and people parameter (level of latent trait); (c) calibration of the people and item parameters (allocation of the parameters on a common scale); and (d) analysis of the item map to define the interpretations referenced to the items. Given that steps (a) and (b) with the same sample were described in a prior study (Zanini $\&$ Peixoto, 2016), the present study will address the results related to steps (c) and (d). Therefore, the objectives of the present study were as follows: (a) to establish interpretive norms and cut-off points for the social support scale (MOSSSS) by means of an analysis of the Item Map, based on Item Response Theory (IRT).

\section{Method}

\section{Participants}

The sample for this study comprised 998 participants of both sexes ( $65.1 \%$ female), aged between 12 and $73(M=27.18, S D=9.90)$, of which $61.7 \%$ were university students; $14.7 \%$ patients being treated for infertility; $10.1 \%$ patients being treated for dietary disorders and obesity; $8.7 \%$ patients subjected to bariatric surgery and $4.8 \%$ patients being treated for burns, As for the patients' level of schooling, 4.9\% of participants were educated to an elementary level only, $61.32 \%$ incomplete higher education, $16.5 \%$ high school, $15.03 \%$ completed higher education. With regard to marital status, $64.4 \%$ were single, $31.6 \%$ married, $3.2 \%$ were separated or divorced and $0.9 \%$ were widowed. In terms of the origins of the participants, the university students came from four higher education establishments, two of which were private schools in 
upstate São Paulo, one was a private school located in the city of São Paulo and the other was a public school from the state of Goiás. The sampling stratum comprising patients, came from day clinics located in the state of Goiás.

\section{Tool}

Social Support Scale (MOS-SSS) developed for the Medical Outcomes Study by Sherbourne and Stewart (1991), adapted for the Brazilian population by Griep's team in the Pró-Saúde (pro-health) study in Rio de Janeiro (Griep et al., 2005). The tool is made up of 19 questions that the participant must answer based on an initial instruction: "If you need it, how often can you depend on somebody to help?", ticking one of the five possible responses according to a fivepoint Likert scale: 0 ("never"); 1 ("seldom"); 2 ("sometimes"); 3 ("almost always") and 4 ("always"). Although there are no standardization studies for the Brazilian population, it is assumed that higher indices for the total score for the respective factors indicate greater perceived support. It should be stressed that, for the sum of the total score, it is not necessary to invert any of the items (Zanini et al., 2009).

\section{Procedures}

Data Analysis. Using the PCM, a Joint maximum likelihood estimation method, the item-person maps were estimated, for interpretation with reference to the item (Embretson \& Reise, 2000). It should be emphasized that the maps were developed separately for each of the four factors making up the MOS-SSS, in respect of the assumptions of one-dimensionality and local independence required by this model. The analyses were performed using the statistical package WINSTEPS version 3.30.0 (Linacre, 2015), using the whole sample. This decision was underpinned by the invariance assumptions already observed by Zanini and Peixoto (2016), as well as by the fact that the item map procedure compares the characteristics of the subjects (estimated level of theta) with the characteristics of the items on the scale (difficulty), distinct therefore from the comparison of scores presented by a subject with those observed by a standardized group (Embretson \& Reise, 2000).

Data Collection. Data collection was performed individually in the specific sample groups in the same health units where they provided healthcare, and collectively for the university students in their classrooms. In all sample groups, the average time allowed to respond to the questionnaire was 15 minutes. All the study participants were invited to take part, receiving an explanation of the objectives and risks of their participation in the survey. All of them were asked to listen to a reading of the Free and Informed Consent Form and after signing said form, the collection of data began. Confidentiality of data was guaranteed as was the possibility of withdrawal from the survey at any time without obligation, observing all the ethical procedures advocated by the APA and Resolution 196/1996.

\section{Results}

Figure 1 displays the item map for the emotional/informational factor, their presentation and interpretation being standardized. Accordingly, on the maps, the items are presented in order of difficulty, the item most easily specified by the participants being located at the foot of the map, observing an increasing order of difficulty, the most difficult appearing at the top of the map. As far as the use of symbols is concerned, ":" represents the transition point for the probability of choosing the response option, due to the subject's level of theta (e.g. at what level of theta the subject probably decides not to tick option 1, but option 2 instead). Moreover, three lines are shown below the map: the first, entitled 'people' which represents the frequency of people located at each point on the $\theta$ scale (the values being read in a vertical direction), the second line 'statistics' represents the descriptive statistics of $\theta$ of the participants, the mean being represented by the letter $(\mathrm{M})$, standard deviation (S) and two standard deviations (T). Lastly, the third line 'percentile' indicates the percentage of subjects allocated to each point on the $\theta$ scale. 


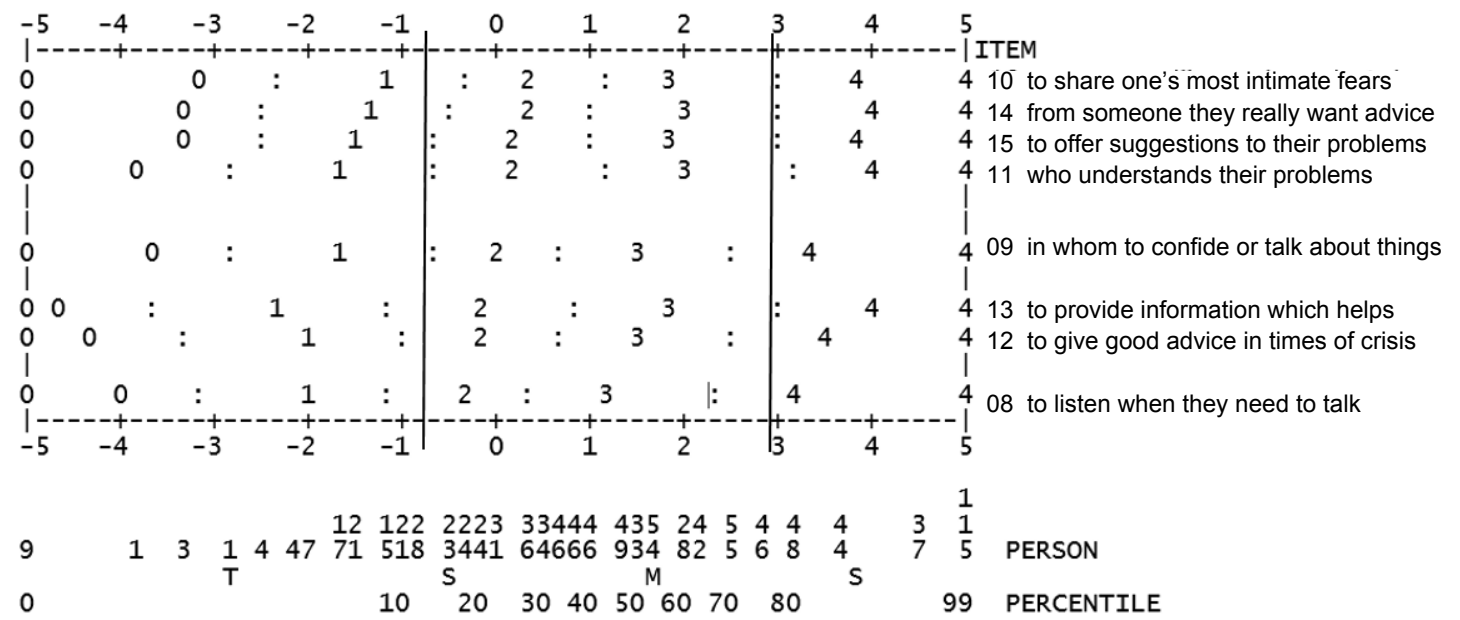

Figure 1. Item map for the Emotional/Informational factor. Note. NB: items are abbreviated, simply transmitting the main concept.

Notably, the majority of people exhibited an approximate level for $\theta$ between -0.6 (S) and 3.8 (S), showing that people tend to agree more than they disagree with the content of the items making up this factor, resulting in a distribution shift towards the positive side of the scale. It should be remembered that the factor evaluates the perception of Emotional/Informational support received from other people; in this context the fragility of the person being evaluated is theoretically shown by low scores for these items.

As observed in Figure 1, people with a mean level of $\theta$, approximately 1.6 , tend to have people on whom they can "almost always" depend in situations described through the item content, specifying option 3 on the Likert scale for all items that comprise the factor. People with a level of $\theta$ one standard deviation below the mean, approximately 0.6 , tend to specify option 2 on the Likert scale in the item band that goes from item 8 to item 14, stating that they "sometimes" have someone on whom they can depend in the situations expressed by the items. However, there is a $50 \%$ probability of specifying options 1 "seldom" or 2 "sometimes" with regard to having someone from whom they really want advice (item 14), and specifying option 1 "seldom" I have someone with whom I can share my most intimate fears (item 10). At the other end of the scale, people with level of $\theta$ one standard deviation above the mean, approximately 3.8 , tend to specify option 4 on the Likert scale, "always" having someone on whom they can depend in the situations described by the items.

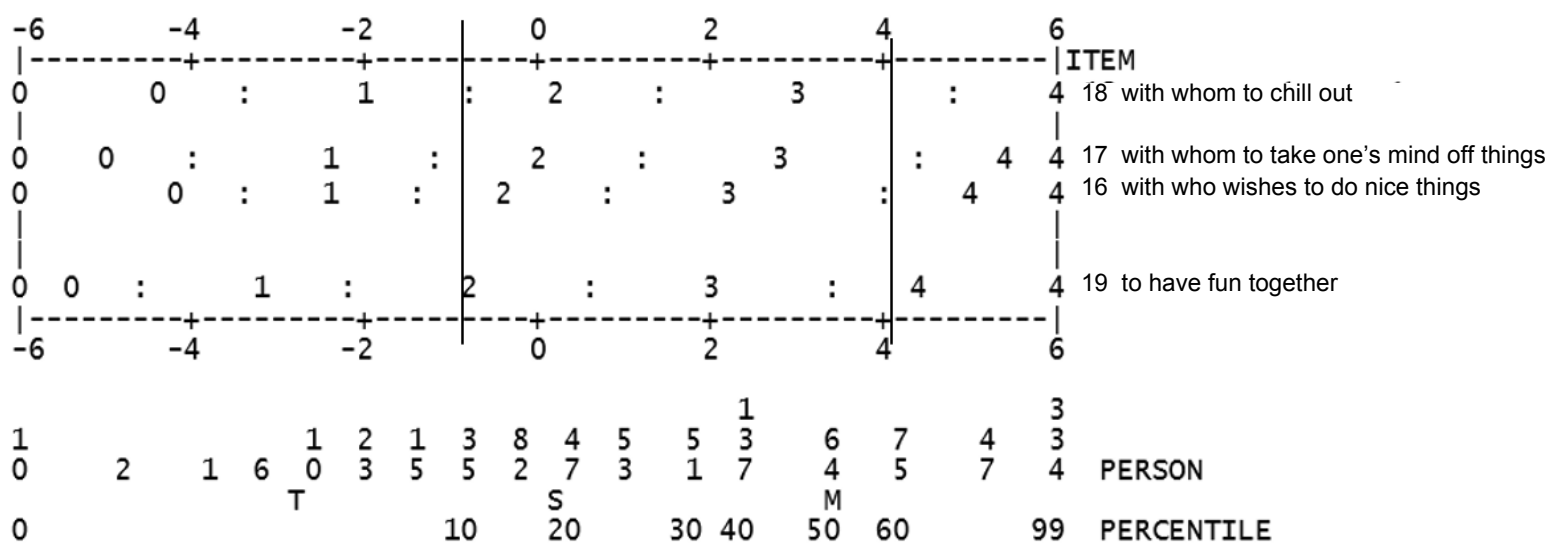

Figure 2. Item map for the Social Interaction factor. Note. NB: items are abbreviated, simply transmitting the main concept. 
As for the factor Social Interaction, Figure 2 displays a greater dispersion when at people's level of $\theta$, accordingly the scale ranges from -6 to +6 . For this factor, people with a mean level of $\theta$, approximately 3.2 , have a $50 \%$ probability of specifying option 3 "almost always" or option 4 "always" in respect of having someone with whom to have fun together, and they also tend to specify option 3 "almost always" in respect of having someone with whom they wish to do nice things (item 16), with whom to take one's mind off things (item 17), and with whom to chill out (item 18). Meanwhile, people with a level of $\theta$ one standard deviation below the mean, approximately 0.2 , tend to specify option 2 , noting that they "sometimes" have someone on whom they can depend in the situations described by the items. Notably, this is a factor which contains items that are easier to specify, given that people with mean levels of $\theta$ can already specify option 4 which represents a greater intensity in the trait being evaluated.

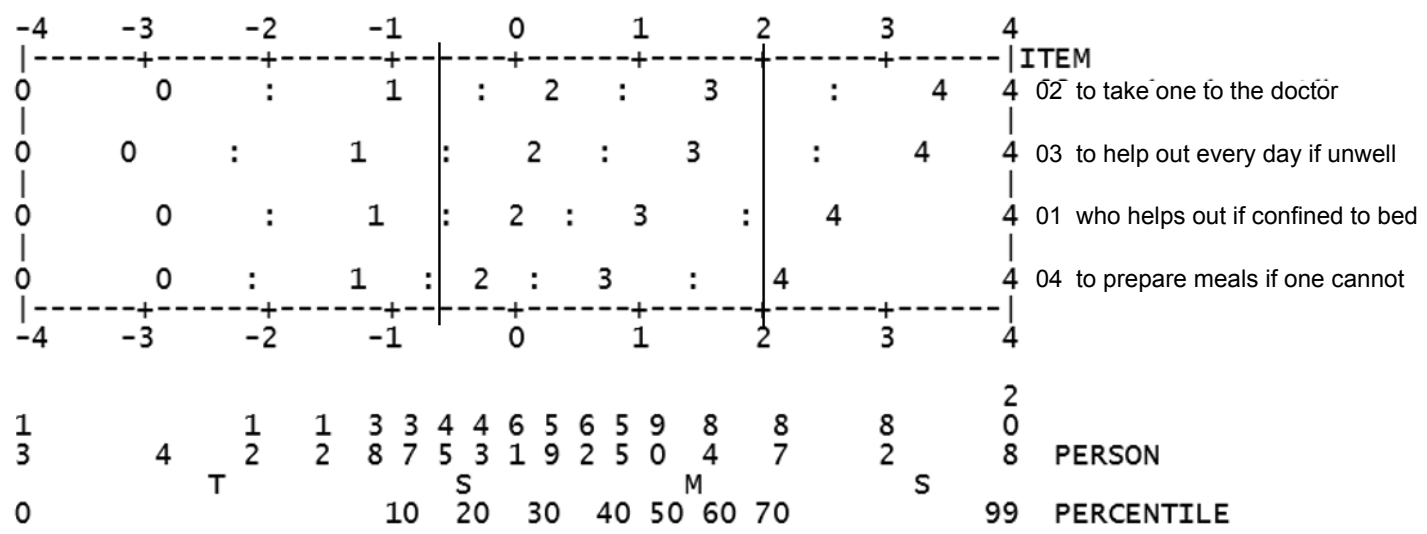

Figure 3. Item map for the Material factor.

Note. NB: items are abbreviated, simply transmitting the main concept.

In the Material factor (Figure 3), the majority of people demonstrated a level of $\theta$ between -0.8 and 3, approximately, showing as with the other factors, people tend to agree more than they disagree about the item content. Thus, people with a level of $\theta$ close to the mean, approximately 1.5 , tend to specify option 3 on the Likert scale "almost always" with regard to having someone on whom they can depend when presented with the situations described by the items that make up the factor. People with a level of $\theta$ one standard deviation below the mean tend to specify option 2 for the range of items that includes items 4,1 and 3 (in order of difficulty), and specify option 1 on the Likert scale "seldom", I have someone on whom I can rely to take me to the doctor's (item 2). On the other hand, people with levels of $\theta$ one standard deviation above the mean tend to specify option 4 "always" for all the items that make up the factor.

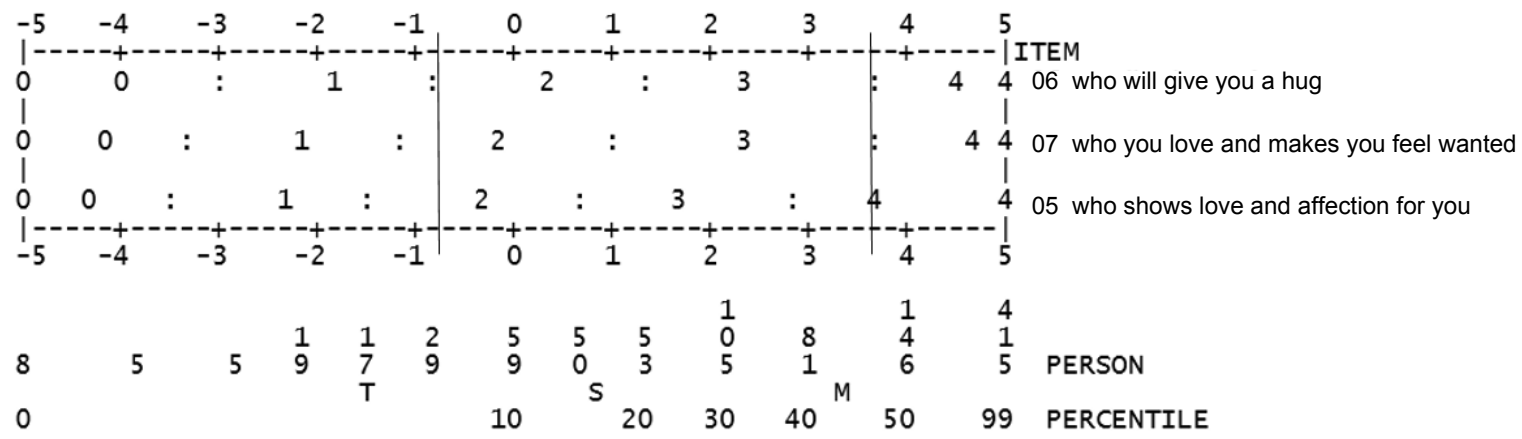

Figure 4. Item map for the Affective factor.

Note. NB: items are abbreviated, simply transmitting the main concept. 
Lastly, the Affective factor, Figure 4, is also characterized by having easier items. People with a level of $\theta$ close to the mean of 3.3, tend to specify option 4 "always" with regard to depending on someone who shows love and affection (Item 5) and option 3 on the Likert scale (almost always) with regard to depending on someone who loves you and makes you feel wanted (item 7) and who will give you a hug (item 6). On the other hand, a person with level of $\theta$ one standard deviation below the mean tends to specify option 3 "almost always" for item 5, and option 2 "sometimes" for items 7 and 6 (in order of difficulty).

In order to enable a comparison of the results of one person evaluated with those obtained through a standardized sample, the procedure was employed that has the aim of transforming the total score into $\theta$. The indicators for this procedure are displayed in Table 1, namely the possible scores obtained through the four factors making up the MOS-SSS, the equivalence in terms of level of $\theta$ of these scores, and the percentiles related to each.

Using the procedure for transforming the total score into a level of $\theta$, it becomes possible to establish cut-off points based on total score and, therefore, the practical application of knowledge arising from the item-person map procedure (Primi, et al., 2014). According to Table 1, it can be seen that, for the emotional/informational factor, the scores can vary between 0 and 32 with levels of $\theta$ varying between -5.97 and 5.74. Based on item content, it was determined that people with a level of $\theta$ up to -0.7 (or total score of 12) should be classified as having a low level of perception of social support of the Emotional/informational type, as they had a higher probability of specifying option 2 "sometimes" for the item band that contains items 8, 12 and 13, and option 1 "seldom" for the items that comprise items 9 , $11,15,14$ and 10. Individuals with a level of $\theta$ between -0.6 and 2.9 (or a total score between 13 and 28) should be classified as having an average level of support, as they have a higher probability of specifying options 2 or 3 for the items that make up the factor. Lastly, people with levels of $\theta$ higher than 3 (a total score above 13) should be classified as having a high level of social support, given the probability of specifying option 4 "always" for all items.

For the social interaction factor, the scores varied between 0 and 16, and the associated levels of $\theta$ varied between -6.18 and 6.72. It was determined that people with a level of $\theta$ up to -0.9 (or a total score of 6) should be classified with a low level of perception of social support of the social Interaction type, given the probability of them specifying option 2 "sometimes" for item 4, and option 1 "seldom" for items 1, 3 and 2. Individuals with a level of $\theta$ between -0.8 and 3.99 (or a total score between 7 and 13) should be classified with an average level of perception of support due to the higher probability of them specifying option 2 "sometimes" and option 3 "almost always" for the four items that make up the factor. As for the people with a level of $\theta$ higher than 4 (a total score greater than or equal to 14), these should be classified with a high level of support, given the higher probability of them specifying option 4 "always" for items 4 and 1, and specifying option 3 "almost always" for items 3 and 2 .

For the Material factor, the scores range from 0 to 16, with associated levels of $\theta$ between -4.16 and 4.25 . It was determined that people with a level of $\theta$ up to -0.7 (or a total score up to 6) should be classified with a level of perception of support of the Material type, since they have a higher probability of specifying option 2 "sometimes" for the item that presents a lower intensity of trait 4, and option 1 for the remaining items: 1 , 3 and 2. People with levels of $\theta$ between -0.6 and 1.99 (or total score between 7 and 13) should be classified with an average level of perception of support due to the higher probability of specifying option 2 "sometimes" and option 3 "almost always" for the four items that make up the factor. Lastly, people with a level of $\theta$ greater than or equal to 2 (or total score greater than or equal to 14) should be classified with a high level of perception of support, notably tending to specify option 3 "almost always" for the items with a lower intensity in the construct " 4 - to prepare meals if unable to do so oneself" and " 1 - who help out if one is confined to bed", and specify 
Table 1

Transformation of the Total Score into Theta, and Percentile

\begin{tabular}{|c|c|c|c|c|c|c|c|c|}
\hline \multirow{2}{*}{ Score } & \multicolumn{2}{|c|}{ Emotional/Inform. } & \multicolumn{2}{|c|}{ Social interaction } & \multicolumn{2}{|c|}{ Material } & \multicolumn{2}{|c|}{ Affective } \\
\hline & Theta & Percentile & Theta & Percentile & Theta & Percentile & Theta & Percentile \\
\hline 0 & -5.97 & 1 & -6.18 & 1 & -4.16 & 1 & -5.19 & 1 \\
\hline 1 & -4.68 & 1 & -4.80 & 1 & -2.89 & 1 & -3.83 & 1 \\
\hline 2 & -3.86 & 1 & -3.83 & 1 & -2.10 & 2 & -2.87 & 1 \\
\hline 3 & -3.33 & 1 & -3.14 & 1 & -1.59 & 3 & -2.15 & 2 \\
\hline 4 & -2.91 & 1 & -2.53 & 2 & -1.20 & 6 & -1.48 & 4 \\
\hline 5 & -2.56 & 1 & -1.97 & 4 & -0.87 & 9 & -0.79 & 6 \\
\hline 6 & -2.25 & 2 & -1.40 & 5 & -0.57 & 13 & -0.08 & 11 \\
\hline 7 & -1.96 & 2 & -0.82 & 8 & -0.29 & 18 & 0.65 & 16 \\
\hline 8 & -1.70 & 3 & -0.22 & 14 & -0.02 & 23 & 1.37 & 22 \\
\hline 9 & -1.45 & 5 & 0.39 & 20 & 0.25 & 29 & 2.11 & 29 \\
\hline 10 & -1.21 & 7 & 1.03 & 25 & 0.54 & 35 & 2.93 & 39 \\
\hline 11 & -0.98 & 9 & 1.72 & 31 & 0.84 & 41 & 4.00 & 50 \\
\hline 12 & -0.76 & 11 & 2.49 & 40 & 1.18 & 48 & 5.44 & 79 \\
\hline 13 & -0.55 & 14 & 3.32 & 50 & 1.59 & 57 & & \\
\hline 14 & -0.34 & 16 & 4.20 & 57 & 2.12 & 66 & & \\
\hline 15 & -0.14 & 19 & 5.29 & 63 & 2.95 & 74 & & \\
\hline 16 & 0.07 & 21 & 6.72 & 83 & 4.25 & 89 & & \\
\hline 17 & 0.27 & 25 & & & & & & \\
\hline 18 & 0.47 & 28 & & & & & & \\
\hline 19 & 0.67 & 32 & & & & & & \\
\hline 20 & 0.87 & 37 & & & & & & \\
\hline 21 & 1.07 & 42 & & & & & & \\
\hline 22 & 1.28 & 46 & & & & & & \\
\hline 23 & 1.50 & 51 & & & & & & \\
\hline 24 & 1.72 & 55 & & & & & & \\
\hline 25 & 1.96 & 59 & & & & & & \\
\hline 26 & 2.22 & 63 & & & & & & \\
\hline 27 & 2.50 & 67 & & & & & & \\
\hline 28 & 2.82 & 73 & & & & & & \\
\hline 29 & 3.20 & 77 & & & & & & \\
\hline 30 & 3.70 & 82 & & & & & & \\
\hline 31 & 4.48 & 86 & & & & & & \\
\hline 32 & 5.74 & 94 & & & & & & \\
\hline
\end{tabular}

Note. The different color shades correspond to the cut-off points set for the factors low, medium and high. 
option 3 "almost always" for the more intense items " 3 - to help out on a daily basis if unwell" and "to take one to the doctor's".

For the Affective factor, the scores varied between 0 and 12, with associated levels of $\theta$ ranging from -5.19 to 5.44 . It was determined that people with a level of $\theta$ up to -0.8 (or total score of 4) should be classified with a low level of perception of support of the affective type, since they have a higher probability of specifying option 2 for the less intense items " 5 - who demonstrates love and affection for you" and "7- who you love and makes you feel wanted", and specifies option 1 "seldom" for the item " 6 who gives you a hug". People with a level of $\theta$ between -0.7 and 3.7 (or total score between 5 and 10) with an average level of perception of support, due to the higher probability of specifying option 2 "sometimes" and option 3 "almost always" for the three items that make up the factor. Lastly, people with levels of $\theta$ greater than or equal to 3.8 (or a total score greater than or equal to 11) should be classified with a high level of perception of support, as they notably tend to specify option 4 "always" for all the items.

\section{Discussion}

The present study sought to establish interpretive norms and cut-off points for the MOSSSS vis-à-vis the Brazilian population. To this end, the PCM was employed, more specifically the item-person Map procedure for interpretation referenced to the item. The results show different levels of difficulty for each of the factors analyzed by the tool. The factors containing items with higher levels of difficulty and, therefore, in which the participants tend to produce the least number of affirmative responses, are social support of the Emotional and Informational and the Material Support types. However, the social support factors of the positive Social Interaction and Affective types were seen to be easier and therefore, had a higher probability of the participant replying positively. These data show that, for the studied sample, there is a higher perception of the existence of people in their social network that love them (Affective support) and with whom they can enjoy moments of pleasure and relaxation (Social Interaction), however, there is a lower perception of the possibility of having someone they can rely upon to share their concerns and feelings (Emotional Support), ask for information (Informational) and support them with practical measures (Material Support).

It should be stressed that this scale evaluates the perception of the existence of social support, but not its effectiveness or measure. Accordingly, the data demonstrate that the participants have higher perception of affective support but they do not indicate the number of people available to provide this support. It could be that the perception being evaluated by this tool is related to a single social relationship, for instance between mother and daughter, and that this relationship is perceived as sufficiently powerful for the participant to indicate a high level of existence of this type of support. This debate has already been pointed out in other studies on the topic that measure the perception of support and not the support itself (Schwarzer \& Knoll, 2007). On the other hand, the perception of the type of social support, such as Material support, could be influenced by the participants' levels of demand. In this way, despite its existence, it may not be evaluated as sufficient to the point of producing a positive response in the tool. These aspects should be taken into consideration when interpreting the data and are in agreement with what has been described in the literature (Queiroz \& Zanini, 2011).

Moreover, the analysis of differences in the levels of theta and the probability of specifying the items that make up each of the factors, confirm this discussion. For example, analyzing Figure 1 in greater detail, with the distribution of the levels of difficulty of each item, a significant conceptual difference can be seen between item 8 (to what extent can someone be depended upon to listen if needed), regarded as the easiest, and therefore having a higher probability of very positive responses, and items 10 (someone with whom to share one's most intimate fears) and 14 (someone from whom one really wants advice). In these items (10 and 14) the probability of very positive responses is diminished showing that, 
although the participants may have evaluated as easier the existence of social support of the Emotional/Informational type, it is not every type of support that is easily perceived. Although there may have been greater availability of people to give advice, this advice is not necessarily desired from all of them and this does not always mean that there is availability of people to share one's intimate fears. This discussion again evidences the distinction between social networks and social support networks (Zanini et al., 2009) and the discussion on the levels and types of social interaction, and their impact on people's wellbeing (Kraut et al., 1998).

This aspect is well demonstrated by Table 1 where the gross scores and their corresponding theta and percentile levels can be observed. The different levels of shading show the lowest, mean and highest indices and provide a visually highlighted parameter to interpret the data in this tool. This difference allows us to locate the scores of an individual in the tool in comparison with the sample, in terms of expected responses by means of their level of theta (Embretson, 2000; Linacre, 2015).

In short, the present study provided normative data for the interpretation of scores on the MOS-SSS scale. This interpretation can be made, particularly, by taking Table 1 as the locator of the respondent's score and the corresponding score on the theta scale. However, the data in this study should be treated with caution as, although they represent current statistical analyses that aim to minimize the effects of sampling error, the sample employed was not selected probabilistically and, therefore, is not representative of the Brazilian population. Nevertheless, the present study may be of great value to psychologists and professionals in the area, who wish to make use of this tool and obtain comparison parameters for this measure.

\section{References}

Andrade, C. R., Chor, D., Faerstein, E., Griep, R. H., Lopes, C., \& Fonseca, M. J. M. (2005). Apoio social e auto-exame das mamas no Estudo Pró-Saúde. Cadernos de Saúde Pública, 21(2), 379-386. doi.org/10.1590/S0102311X2005000200004
Cobb, S. (1976). Social support as a moderator of life stress. Psychosomatic. Medicine, 38(5), 300314. Retrieved from https://campus.fsu.edu/ bbcswebdav/institution/academic/social_sciences/sociology/Reading\%20Lists/Mental\%20 Health\%20Readings/Cobb-PsychosomaticMed-1976.pdf

Dantas, M. M. C., Araújo, P. C. B., Paulino, B. S., \& Maia, E. M. C. (2012). Avaliação do apoio social e de sintomas depressivos em mães de bebês prematuros hospitalizados. Psicologia em Revista, 18(1), 90-106. doi.org/10.5752/P.16789563.2012v18n1p90

Embretson, S. E., \& Reise, S. P. (2000). Item response theory for psychologists. Mahwah, NJ: Lawrence Erlbaum.

Gómez-Campelo, P., Pérez-Moreno, E., Burgos-Lunar, C., Bragado-Álvarez, C., Jiménez-García, R., \& Salinero-Fort, M. (2014). Psychometric properties of the eight-item modified Medical Outcomes Study Social Support Survey based on Spanish outpatients. Quality of Life Research, 23(7), 2073-2078. doi:10.1007/s11136014-0651-6

Gonçalves, T. R., Pawlowski, J., Bandeira, D. R., \& Piccinini, C. A. (2011). Avaliação de apoio social em estudos brasileiros: Aspectos conceituais e instrumentos. Ciência \& Saúde Coletiva, 16(3), 1755-1769. doi:https://dx.doi. org/10.1590/S1413-81232011000300012

Griep, R. H. (2003). Confiabilidade e validade de instrumentos de medida de rede social e de apoio social utilizados no Estudo Pró-Saúde (Unpublished doctoral dissertation, Escola Nacional de Saúde Pública, Fundação Oswaldo Cruz, Rio de Janeiro, RJ, Brazil).

Griep, R. H., Chor, D., Faerstein, E., Werneck, G. L., \& Lopes, C. S. (2005). Validade de constructo de escala de apoio social do Medical Outcomes Study adaptada para o português do Estudo PróSaúde [Construct validity of the Medical Outcomes Study's social support scale adapted to Portuguese in the Pró-Saúde Study]. Cadernos de Saúde Pública, 21(3), 703-714. doi:10.1590/ S0102-311X2005000300004

Kraut, R., Patterson, M., Lundmark, V., Kiesler, S., Mukophadhyay, T., \& Scherlis, W. (1998). Internet paradox: A social technology that reduces social involvement and psychological well-being?. American Psychologist, 53(9), 1017-1031. doi:http://dx.doi.org/10.1037/0003066X.53.9.1017 
Linacre, J. M. (2015). A user's guide to Winsteps Ministep: Rasch-model computer programs. Retrieved from http://www.winsteps.com

McClarty, K. L. (2013). Construct Maps: A tool to organize validity evidence. Measurement, 11, 185-188. doi:10.1080/15366367.2013.857213

Pais-Ribeiro, J. L., \& Ponte, A. C. S. L. C. (2009). Propriedades métricas da versão portuguesa da escala de suporte social do MOS (MOS Social Support Survey) com idosos. Psicologia, Saúde \& Doença, 10(2), 163-174. Recuperado em https://sigarra.up.pt/fdup/pt/pub_geral.show_ file?pi_gdoc_id=557613

Primi, R., Wechsler, S. M., Nakano, T. C., Oakland, T., \& Guzzo, R. S. L. (2014). Using Item Response Theory methods with the Brazilian temperament scale for students. Journal of Psychoeducational Assessment, 32(7). doi:https://doi. org/10.1177/0734282914528613

Queiroz, I. P. A. R., \& Zanini, D. S. (2011). Apoio social, coping e suas repercussões no humor depressivo. Estudos: Vida e Saúde (Goiânia), 38(1-3), 133-149. Recuperado em http://seer. pucgoias.edu.br/index.php/estudos/article/ view/1919/1204

Santos, D., \& Primi, R. (2014). Social and emotional development and school learning: A measurement proposal in support of public policy (Technical report for Organization for Economic Cooperation and Development [OCDE] Rio de Janeiro State Education Department [SEEDUC] and Ayrton Senna Institute). São Paulo, SP: Ayrton Senna Institute.

Schwarzer, R., \& Knoll, N. (2007). Functional roles of social support within the stress and coping process: A theoretical and empirical overview. International Journal of Psychology, 42(4), 243 252. doi:10.1080/00207590701396641
Sherbourne, C. D., \& Stewart, A. L. (1991). The MOS Social Support Survey. Social Science Medicine, 32(6), 705-714. Retrieved from http:// www.ncbi.nlm.nih.gov/pubmed/2035047

Wyse, A. E. (2013). Construct Maps as a Foundation for Standard Setting. Measurement, 11, 139170. doi:10.1080/15366367.2013.850287

Yun, E. H., Kang, Y. H., Lim, M. K., Oh, J. K., \& Son, J. M. (2010). The role of social support and social networks in smoking behavior among middle and older aged people in rural areas of South Korea: A cross-sectional study. BMC Public Health, 10, 78. doi:http://doi.org/10.1186/14712458-10-78.

Zanini, D. S., \& Peixoto, E. M. (2016). Social Support Scale (MOS-SSS): Analysis of the Psychometric Properties via Item Response Theory. Paidéia (Ribeirão Preto), 26(65), 359-368. doi:https:// dx.doi.org/10.1590/1982-43272665201612

Zanini, D. S., Verolla-Moura, A., \& Queiroz, I. P. A. R. (2009). Apoio social: Aspectos da validade de constructo em estudantes universitários. Psicologia em Estudo, 14(1), 195-202. doi:10.1590/ S1413-73722009000100023

\footnotetext{
Received: 22/04/2016

$1^{\text {st }}$ revision: 08/09/2016

$2^{\text {nd }}$ revision: 03/02/2017

Accepted: 13/03/2017
}

(C) The Author(s), 2018. Open Access. This article is distributed under the terms of the Creative Commons Attribution 4.0 International License (http://creativecommons.org/licenses/by/4.0/), which permits unrestricted use, distribution, and reproduction in any medium, provided you give appropriate credit to the original author(s) and the source, provide a link to the Creative Commons license, and indicate if changes were made. 